\title{
Proposta á otimização da admissão de trabalhadores mediante os princípios básicos
}

\section{da gestão da informação}

Proposal to optimize the admission of workers through the basic principles of information

management

Propuesta para optimizar la admisión de trabajadores a través de los principios básicos de la gestión de la información

Recebido: 19/05/2021 | Revisado:27/05/2021 | Aceito: 01/06/2021 | Publicado: 11/06/2021

Patrícia Lorrany Oliveira Lopes ORCID: https://orcid.org/0000-0002-7174-140X Faculdade de Engenharia de Minas Gerais, Brasil E-mail: lorranyol@hotmail.com

Patrícia Nadir de Miranda

ORCID: https://orcid.org/0000-0002-9480-5410 Faculdade de Engenharia de Minas Gerais, Brasil E-mail: patricianadirdemiranda@yahoo.com.br

Sandro Takeo Caires Iwafune ORCID: https://orcid.org/0000-0002-7622-3783 Faculdade de Engenharia de Minas Gerais, Brasil E-mail: sandrotakeo@gmail.com

Tálita Rodrigues de Oliveira Martins ORCID: https://orcid.org/0000-0002-3850-5042 Faculdade de Engenharia de Minas Gerais, Brasil E-mail: thalita.rodrigues@feamig.br

\begin{abstract}
Resumo
Esse artigo discorre sobre um tema que, segundo o representante da empresa UPTEC Construção e Tecnologia Ltda. (UPTEC) têm sido um gargalo entre o setor de produção e o admissional: a liberação do trabalhador, mesmo após este ter sido aprovado para se admitido na empresa. O problema é que alguns trabalhadores tendem a não apresentar dois tipos de certificados de porte obrigatório em áreas da elétrica, segundo a Norma Regulamentadora (NR), NR-10, item 10.8/Treinamento, posta na Portaria Ministerial no 3.214/Segurança e Medicina do Trabalho (SMT) (BRASIL,1978): um é relativo a curso básico, onde se ministra as regras básicas sobre o trabalho em eletricidade, tipo os direitos e os deveres em áreas da prevenção e o outro curso é sobre o Sistema Elétrico de Potência (SEP), onde temas relacionados à profissão, tipo como trabalhar de maneira segura com vistas a produtividade. Para realizar esse estudo fez-se uma coleta de dados e de informações via e-mail para alguns trabalhadores da área da elétrica, com vistas saber destes como foi o momento da apresentação/entrega dos certificados requeridos no item 10.8/NR-10. Para processar os dados utilizou-se o sistema operacional Windows ${ }^{\circledR}$, na plataforma Excel, para tabular e algumas ferramentas da qualidade, tipo a folha de verificação, o histograma, o gráfico de Pareto. Os resultados do estudo apontaram que a utilização de ferramentas da qualidade pode auxiliar na tomada de decisões gerenciais e como proposta à melhoria do processo admissional, um plano de ação foi elaborado.
\end{abstract}

Palavras-chave: Engenharia de produção; Gestão da informação; Área elétrica; NR-10/10.8; Gargalo.

\begin{abstract}
This article discusses a topic that, according to the representative of the company UPTEC Construção e Tecnologia Ltda. (UPTEC) have been a bottleneck between the production sector and the admission: the release of the worker, even after he has been approved to be admitted to the company. The problem is that some workers tend not to present two types of certificates of mandatory possession in electrical areas, according to the Regulatory Standard (NR), NR-10, item 10.8/Training, posted in Ministerial Ordinance No. 3.214/Safety and Medicine of the Work (SMT) (BRASIL, 1978): one is related to a basic course, where the basic rules about work in electricity are given, such as rights and duties in areas of prevention and the other course is about the Electric Power System (SEP), where topics related to the profession, such as how to work safely with a view to productivity. In order to carry out this study, data and information were collected via e-mail for some workers in the electrical sector, with a view to knowing how they were presenting / delivering the certificates required in item 10.8 / NR-10. To process the data, the Windows ${ }^{\circledR}$ operating system was used, on the Excel platform, to tabulate and some quality tools, such as the check sheet, the histogram, the Pareto graph. The results of the study pointed out that the use of quality tools can assist in making managerial decisions and as a proposal to improve the admission process, an action plan was developed.
\end{abstract}

Keywords: Production engineering; Information management; Electrical area; NR-10/10.8; Neck. 


\section{Resumen}

Este artículo trata un tema que, según el representante de la empresa UPTEC Construção e Tecnologia Ltda. (UPTEC) han sido un cuello de botella entre el sector productivo y la admisión: la liberación del trabajador, incluso después de haber sido aprobado para ser admitido en la empresa. El problema es que algunos trabajadores tienden a no presentar dos tipos de certificados obligatorios en las áreas de energía eléctrica, según Norma Reglamentaria (NR), NR-10, ítem 10.8 / Capacitación, colocada en la Ordenanza Ministerial No. 3.214 / Seguridad y Medicina del Trabajo (SMT) (BRASIL, 1978): uno está relacionado con un curso básico, donde se enseñan las reglas básicas sobre el trabajo en electricidad, como derechos y deberes en áreas de prevención y el otro curso es sobre el Sistema Eléctrico de Energía (SEP ), donde se tratan temas relacionados con la profesión, como cómo trabajar de forma segura con vistas a la productividad. Para la realización de este estudio se recabaron datos e información vía e-mail de algunos trabajadores del sector eléctrico, con el fin de conocer cómo estaban presentando / entregando los certificados requeridos en el ítem 10.8 / NR-10. Para procesar los datos se utilizó el sistema operativo Windows $®$, en la plataforma Excel, para tabular y algunas herramientas de calidad, como la hoja de verificación, el histograma, el gráfico de Pareto. Los resultados del estudio señalaron que el uso de herramientas de calidad puede ayudar en la toma de decisiones gerenciales y como propuesta para mejorar el proceso de admisión se desarrolló un plan de acción.

Palavras clave: Ingeniería de producción; Gestión de la información; Área eléctrica; NR-10/10.8; Cuello.

\section{Introdução}

Para muitos trabalhadores a busca por uma nova ou inicial oportunidade de trabalho e passar por um processo admissional pode não ser um momento muito fácil, principalmente pela falta de conhecimento complementar para determinadas áreas, por exemplo, em assuntos relacionados à SMT (DUNDER, 2020). Para suprir esse tipo de falta, conforme requer o Artigo 157 da Lei Federal n 6.514, de 22 de dezembro de 1977 (BRASIL, 1977) posta pelo Ministério do Trabalho e Emprego (MTE), cabe ao empregador/gestor do Fluxo de Processo de Produção (FPP) apresentar ao novo trabalhador quais são as exigências da empresa, os direitos e os deveres trabalhista.

Vale destacar que o gestor do FPP precisa reconhecer o que atrapalha o desenvolvimento normal do processo e trabalhar as deficiências com vistas corrigí-las adequadamente. Ou seja, sugere-se que o gestor do FPP pratique o Princípio Básico da Gestão da Informação (PBGI) que é, segundo Silva; Tomaél (2007) coletar, processar e disponibilizar a informação à tomada de decisão mais assertiva pelo gestor do processo.

Para atender a legislação em matéria de SMT, quando o processo admissional do trabalhador em áreas da elétrica é pausado pela falta da entrega de certificados pré-vistos no item 10.8/Treinamentos/NR-10, antes, deve-se providenciá-los à inserção de fato do trabalhador em qualquer das etapas do FPP. (BRASIL, 1978)

Esse estudo visa propor melhoria no processo de admissão dos trabalhadores e para isso os temas Gestão da Informação (GI), algumas ferramentas da qualidade e uma gerencial do tipo 5W2H/Plano de Ação foi apresentada como proposta à otimização do processo admissional. O problema que serviu como norte à reallização desse estudo consistiu no saber como otimizar a etapa de admissão para atender o item 10.8 da NR-10/Treinamento posta na Portaria Ministerial $\mathrm{n}^{\circ}$ 3.214 (BRASIL, 1978), na UPTEC?

Sobre os objetivos, o geral consistiu no identificar de que maneira a entrega dos documentos ou certificados relativos ao item 10.8 da NR-10/Treinamento pode ser mais eficiente na admissão de trabalhadores, para que a liberação destes seja mais ágil para o setor de produção. Para isso: a)Levantou-se os motivos que levam os trabalhadores atrasar a entrega de documentos alusivos ao item 10.8 da NR-10/Treinamento, no momento da admissão destes: b)Priorizou-se o(s) motivos(s) que contribue(m) para o atraso da entrega de documentos requeridos à admissão de eletricistas, por meio de ferramentas da qualidade, e c)Apresentou-se uma proposta para otimizar o processo admissional mediante a etapa "P" do ciclo PDCA. Para realizar o estudo de caso, os dados e as informações foram obtidas via e-mail devido a impossibilidade do contato presencial, em razão da epidemia CoVid-19/Distanciamento social. 


\section{Metodologia da Pesquisa}

Essa pesquisa é do tipo aplicada, onde dos resultados elaborou-se uma proposta à melhoria do processo avaliado. Segundo Gil (2017), na pesquisa aplicada o pesquisador visa resolver um problema e para isso explora conhecimentos e gera produtos e/ou processos com a finalidade de ser aplicada.

Quanto à natureza da pesquisa, pesquisa quali-quantitativa, porque o fenômeno foi quantificado e qualificado com vistas apresentar valores e considerações teóricas. A pesquisa quali-quantitativa, segundo Minayo (1997), consiste em uma completar a outra, o fenômeno é analisado de maneira mais profunda e visa um aspecto prático.

Quanto aos fins é uma pesquisa exploratória, onde os pesquisadores buscaram saber de quem participou da pesquisa como foi o momento da entrega de seus certificados/cursos em áreas da elétrica. Jung (2004) e Gil (1994) salienta que esse tipo de pesquisa envolve a familiarização mais profunda com o fenômeno, seja em livros ou na web. Em relaçao aos meios é um estudo de caso porque trata de uma situação real, onde os pesquisadores entraram em contato com alguns trabalhadores para saber como foi o momento da apresentação/entrega de certificados de cursos obrigatórios quando foram admitidos na empresa.

Para coletar dados empregou-se um questionário via e-mail com questões abertas e fechadas. O questionário “[É] um instrumento de coleta de dados constituído por uma série ordenada de perguntas, que devem ser respondidas por escrito e sem a presença do entrevistador". (MARCONI, 2006, p.98)

\section{Referencial Teórico}

\subsection{Gestão}

Gestão é quando o gestor planeja as ações futuras, com intuito de executar e controlar o que ocorre em um processo, com vistas atingir os objetivos da organização e melhorar o processo. (CATELLI,1999 apud SANTOS, 2010)

Segundo Harrington (1993), geralmente os grupos dentro das organizações estão preocupados e concentrados em suas funções, para que possam atingir suas metas e, às vezes, não se preocupam na maneira como suas atividades podem interferir em outros setores. Devido a isso, diversos gestores têm buscado adequar os processos com os novos modelos de gestão, com vistas melhorar a qualidade serviços e, consequentemente, melhorar seu desempenho perante ao mercado.

\subsubsection{Considerações acerca do papel do gestor em áreas da engenharia}

De acordo com a Resolução 1010, de 22 de agosto de 2005, que discorre sobre a regulamentação da atribuição de títulos profissionais em áreas da engenharia, Capítulo - II, Art. 5o, o Engenheiro de Produção/Gestor deve, entre outras atribuições, administrar, supervisionar, coordenar, orientar tecnicamente em qualquer das EPP, além de estar preparado para coletar dados, efetuar estudos, planejar, projetar e até especificar algo em um processo. (CONSELHO REGIONAL DE ENGENHARIA E AGRONOMIA, 2005)

Para Coutinho (2020), um gestor deve conhecer toda a organização e o EP, segundo Moura (2020, p.1), “[...] deve ter uma visão ampla do processo, entendendo desde gestão de pessoas até elementos mecânicos/elétricos”, pois esse pode apresentar um certo grau de complexidade e de mudanças ocasionais que precisam ser conhecidas.

\subsection{Processos de gestão}

Conforme Gonçalves (2000), a gestão por processos é resultante da introdução da orientação por processos nas empresas. Compreender os tipos existentes de processos e como eles funcionam é importante para determinar a maneira como devem ser gerenciados, a fim de obter o máximo resultado.

Já para Sordi (2008), gestão é uma abordagem administrativa com priorização e foco nos processos. Ou seja, visa propor um conhecimento integrado dos processos de uma organização. Para a implantação da gestão por processo 
independente do porte e do segmento da empresa, se faz necessário entender o objetivo, a estratégia, e principalmente saber quais são os processos atuais, a fim de se obter a busca da satisfação dos clientes. O processo de gestão pode ser dividido em: Gestão da produção; Gestão da informação e Gestão da qualidade.

\subsubsection{Processo de gestão da produção}

Aperfeiçoar, ou seja, promover rendimento ótimo em um processo com vistas evitar algum tipo de perda nem sempre é tarefa fácil (SLACK, 2013). Mas em áreas da prevenção estima-se que se o gestor eliminar o(s) fenômeno(s) adversos antes que esse ocorra é possível que gargalos, perdas ou reduções da produtividade na empresa não ocorra. (MAROUELI, 2008)

Em áreas da produção, de acordo com Chiavenato (2014, p.15), um processo "É uma ordenação específica das atividades de trabalho no tempo e no espaço, com começo e fim, entradas e saídas claramente identificadas".

Para corroborar, um processo também pode ser definido em áreas da SMT como, segundo a Norma Brasileira de Regulação (NBR) posta pela Associação Brasileira de Norma Técnica (ABNT); ABNT NBR ISO 45001 (2018), sobre Sistema de Gestão de Saúde e Segurança Ocupacional, requisitos com orientação para uso, no item 3.25: "[um] conjunto de atividades inter-relacionadas ou interativas que transformam entradas em saídas" (ABNT NBR ISO 45001, 2018, p.6).

Carpinetti (2016) recomenda que o gestor planeje as suas ações de maneira possibilitar ou viabilizar o alcance dos objetivos da maneira mais assertiva possível. Chiavenato (2010, p.73) referiu-se a isso da seguinte maneira: "[o gestor deve] planejar, organizar, dirigir e controlar os recursos no sentido de alcançar objetivos e resultados para a organização", da maneira mais assertiva e otimizada possível em qualquer das etapas do fluxo de processo de produção da empresa.

Um FPP consiste na representação gráfica das etapas, de maneira a proporcionar uma visão detalhada da entrada à saída da matéria-prima/insumos. Entender as etapas de um FPP pode "[viabilizar] um entendimento global do fluxo produtivo, permitindo a análise de eventuais falhas e gargalos associados ao mesmo". (DINSMORE; CAVALIERI, 2013, p.144)

\subsubsection{Processo de gestão da informação}

Para Júnior (2014), em um meio social, a informação é uma ferramenta capaz de constatar, transformar e evoluir o pensamento humano e a sociedade. Segundo Ponjuán Dante (1998), no âmbito organizacional, uma empresa que quer se manter no mercado deve tomar as decisões mais assertivas possíveis mediante a GI.

A GI é um processo onde, para Borko (1968), a produção e o uso da informação são praticados por um mesmo individuo em circunstâncias e condições particulares. Tal processo ocorre ao passo que o indivíduo supre sua necessidade de informação e elabora conhecimento, que entrará ou não em outro ciclo, como necessidade para outro individuo. E as etapas básicas da GI consistem em, segundo Silva; Tomaél (2007) e Montagner; Marx (2009): a) Coletar; b)Processar, e c)Disponibilizar os resultados á gestão da empresa/etapa, para que se providencie as decisões mais assertivas possíveis.

\subsubsection{Processo de gestão da qualidade}

Para Camargo (2011), quem pratica a gestão da qualidade visa praticamente dois objetivos: o primeiro é organizar e melhorar de maneira contínua o processo de produção seja no FPP como um todo, seja em qualquer de suas partes; e visa, também apresentar produtos e/ou serviços que atendam aos interesses dos clientes da organização, isso mediante o atendimento a diretrizes normatizadas, principalmente mediante as normas apresentadas pela ABNT, sobre os produtos.

Os produtos, segundo Branjão (2016) representam algo tangível, já os serviços são intangíveis. Presume-se, portanto, que a qualidade tanto em relação a um produto, quanto a um serviço é algo que precisa ser cuidada para se evitar prejuízos e/ou gastos desnecessários, por exemplo, com retrabalhos, com devoluções, reparo e, também para favorecer a geração e/ou a manutenção dos lucros esperados pela organização, seja local ou em âmbito globalizado. 
Lélis (2012) salienta que o comportamento dos clientes tende a ser globalizado, Portanto podem exigir mais em relação à qualidade dos produtos/serviços, isso em função da oferta, o uso e a disponibilidade das novas tecnologias e a consequente disponibilidade de novos produtos/serviços que tem surgido praticamente o tempo todo.

\subsubsection{Ferramentas da qualidade}

De acordo com Alonço (2018, p.1), as ferramentas da qualidade são:

1) A folha de verificação ou Check-list é uma planilha onde se lista o que será observado e quantificado. Pode ser apresentada na forma de uma lista, de uma figura, de tabelas e outros, isso de acordo com Dinsmore; Cavalieri (2013);

2) O gráfico de pareto é um recurso gráfico que foi "[desenvolvido] pelo sociólogo e economista italiano Vilfredo Pareto (1843-1923)", onde sugeriu que após determinado os \%Acum, se os elementos que estiverem na casa dos 20\% ou próximos a essa forem resolvidos, os demais tendem à solução (CARPINETTI, 2016, p.64);

3) O gráfico de contrôle, para Dinsmore; Cavalieri (2013, p.140) representa dos "[...] resultados de um processo ao longo de determinado período utilizada para verificar se o mesmo está dentro de determinadas faixas de referência";

4) O diagrama de causa e efeito ou diagrama espinha de peixe ou diagrama ishikawa, segundo Rodrigues (2004, p.114) "[...] é um diagrama que visa estabelecer a relação entre o efeito e todas as causas de um processo".

5) Diagrama de dispersão. Para Carpinetti (2012, p.89), "[Trata-se de] um gráfico utilizado para a visualização do tipo de relacionamento existente entre duas variáveis"

6) Histograma. Para Rodrigues (2004), trata-se de diagramas de barras verticais que indicam a distribuição da frequência de um conjunto de dados numéricos.

7) Folha de estratificação. Para Carpinetti (2016, p.81), “A estratificação consiste na divisão de um grupo em diversos subgrupos com base em características distintivas ou de estratificação", seja por data, hora, local, semana etc.

\subsubsection{Ferramentas à implementação da melhoria contínua}

Estima-se que a melhoria de um processo pode ser alcançada mediante esforço contínuo, em ciclo e os trabalhadores devem cooperar e interagir de maneira constante. Para Dinsmore; Cavalieri (2013, p.148), "A melhoria contínua é uma abordagem preventiva [e pode ser implantando em] qualquer processo ou procedimento que hoje é satisfatório, no futuro poderá não ser", mas isso requer a participação de todos.

Segundo Kaiser (2020, p.1), "Planejar estrategicamente é pensar o passado, o presente e o futuro, é definir as ações que colocaremos em prática para que os objetivos (desejos) sejam alcançados", mediante o estabelecimento de etapas ou passo-a-passo para se chegar ao objetivo pretendido em qualquer organização, independe do tipo de processo e do tamanho do seguimento. Isso pode ser possível mediante os $5 \mathrm{~W} 2 \mathrm{H}$, que significam: a) What/O que será feito (etapas) b) Why/Por que será feito (justificativa); c) Where/Onde será feito (local); d) When/Quando será feito (tempo); d) Who/Por quem será feito responsabilidade); How/Como será feito (método), e h) How much/Quanto custará fazer (custo) (PERIARD, 2009).

\subsection{A eletricidade}

Segundo Castro (2006, p.3), “A eletricidade não é vista, é um fenômeno que escapa aos nossos sentidos, só se percebem suas manifestações exteriores,

como a iluminação, sistemas de calefação entre outros". Nota-se que a eletricidade, apesar de servir à sociedade em diversas maneiras e de ser extremamente útil nos ambientes é invisível e pode proporcionar riscos à saúde de pessoas em seus locais de trabalho, com objetivo promover, aumentar e/ou beneficiar o(s) processo(s). 
É bom destacar que o eletricista precisa ser devidamente qualificado. Para Castro (2006, p.3), o trabalhador em áreas da elétrica precisa desenvolver e apresentar "[...] o contexto da função e aplicar a melhor técnica de execução em função das características de local, de ambiente e do próprio processo de trabalho".

\subsection{Norma Regulamentadora número 10}

De acordo com Mattede (2020), a NR-10 é uma norma que visa orientar os empregadores e os empregados sobre o que fazer para se evitar AT e DO em áreas da elétrica e não se trata de uma norma nova, ou seja, foi publicada inicialmente na década de 1978, republicada na década de 2004 e no início da década de 2020 novamente passou por consulta pública para novamente ser atualizada.

Dos itens da NR-10 destaca-se: 10.8.1: o profissional deve ter a qualificação comprovada para poder trabalhar em atividades da elétrica e a empresa precisa comprovar que o funcionário fez o tipo de curso mediante a apresentação de certificado; 10.8.8.2: além da comprovação de qualificação, a empresa deve promover a reciclagem periódico; 10.8.8.4: todo trabalhador em área da elétrica, dependendo do trabalho que irá executar deve ser previamente qualificado à tarefa que será executada, portanto será preciso treiná-lo adequadamente e a empresa fornecer o devido certificado de curso,seja o curso básico, seja o curso Sistema Elétrico de Potência (SEP).

\section{Análise e Resultados}

4.1 Levantamento dos motivos que levam os trabalhadores a atrasar a entrega de documentos alusivos ao item 10.8 da NR-10/Treinamento, na admissão na empresa

Inicialmente, para reconhecimento do cenário fez-se um levantamento sobre se os respondentes (12) apresentaram ou não os certificados dos cursos Básico e SEP no momento em que foram admitidos na empresa.

Sobre o curso Básico dos 12 Respondentes (R), 8 mencionaram que apresentaram o certificado e 4 "Não". Sobre o curso SEP, dos 12 R, 3 afirmaram ter apresentado o respectivo certificado e 8 optaram pelo "Não" como resposta. Nesse cenário apenas as 12 respostas "Não" foram postas sobre análise.

É importante lembrar dois aspectos: um é que para um eletricista exercer suas atividades na empresa, este profissional tem de participar do curso básico e caso seja necessário, do curso SEP (ESCOLA NACIONAL DA INSPEÇÃO DO TRABALHO, 2020). O outro relaciona-se ao FPP: o gestor, segundo Catelli (1999 apud SANTOS, 2010), deve controlar as particularidades de cada uma etapa do FPP sob seus cuidados, com vistas identificar o(s) gargalo(s) e eliminá-lo(s).

4.2 Priorização do(s) motivos(s) que contribue(m) para o atraso da entrega de documentos à admissão de eletricistas, por meio de ferramentas da qualidade

Após levantar os motivos (12) que contribuem para o atraso da entrega de documentos/certificados, esses foram estruturados nos conceitos teóricos de Carpinetti (2016), sobre a Folha de Verificação, confomre indica a etapa "A” posta na Tabela 1: 
Tabela 1 - Processamento dos dados e das informações da pesquisa.

\begin{tabular}{|c|c|c|c|c|c|}
\hline & A & \multicolumn{2}{|c|}{ B } & & C \\
\hline & MOTIVOS NA ORDEM INICIAL & \multicolumn{2}{|c|}{ FREQUENCIA } & & TOTAL \\
\hline a & O Recurso Humano näo informou quais eram as obrigaçōes; & \multicolumn{2}{|c|}{$\mathrm{XXX}$} & & 3 \\
\hline b & Para eles, tanto fazia ter ou năo os certificados; & \multicolumn{2}{|c|}{$\mathrm{X}$} & & 1 \\
\hline c & Pensaram que os cursos eram ministrados na empresa; & \multicolumn{2}{|c|}{$\mathrm{xX}$} & & 2 \\
\hline d & Năo guardaram os certificados; & \multicolumn{2}{|c|}{$x$} & & 1 \\
\hline $\mathrm{e}$ & Faltou informaçōes prévia sobre a necessidade de apresentar os certificados; & \multicolumn{2}{|c|}{$\mathrm{x}$} & & 1 \\
\hline \multirow[t]{4}{*}{1} & \multirow[t]{2}{*}{ Năo sabiam que tais certificados eram requeridos pela empresa. } & \multirow{2}{*}{\multicolumn{2}{|c|}{$\mathrm{XXXX}$}} & & 4 \\
\hline & & & & $\Sigma=$ & 12 \\
\hline & $\mathbf{E}$ & D & $\mathrm{F}$ & & G \\
\hline & MOTIVOS PRIORIZADOS & $\begin{array}{l}\text { Ordem } \\
\text { decte }\end{array}$ & $\begin{array}{c}\% \\
\text { Unit. }\end{array}$ & \multicolumn{2}{|c|}{$\begin{array}{c}\% \\
\text { Acum. }\end{array}$} \\
\hline$f$ & Nāo sabiam que tais certificados eram requeridos pela empresa. & 4 & 33,33 & & 33,33 \\
\hline a & O Recurso Humano năo informou quais eram as obrigaçöes; & 3 & 25,00 & & 58,33 \\
\hline c & Pensaram que os cursos eram ministrados na empresa; & 2 & 16,67 & & 75,00 \\
\hline b & Para eles, tanto fazia ter ou não os certificados; & 1 & 8,33 & & 83,33 \\
\hline d & Nâo guardaram os certificados: & 1 & 8,33 & & 91,67 \\
\hline e & Faltou informaçōes prévia sobre a necessidade de apresentar os certificados; & 1 & 8,33 & $\Sigma=$ & 100,00 \\
\hline & $\Sigma=$ & 12 & $\overline{100,00}$ & & \\
\hline
\end{tabular}

Fonte: Carpinetti (2016). Adaptado pelos autores (2021).

A Tabela 1 ilustra de que maneira os motivos alusivos ao atraso da entrega dos certificados sobre os cursos Básico e SEP à empresa foram processados. Da coluna "A" a "C") observa-se uma Folha de Verificação e das colunas "E" a "G" tem-se os quesitos priorizados e a base de cálculo destinado à elaboração do Grárico de Pareto. Após determinado quais são os \%Unit. e os \%Acum., os motivos ficaram priorizados da seguinte maneira na Figura 1:

Figura 1 - Gráfico de pareto.

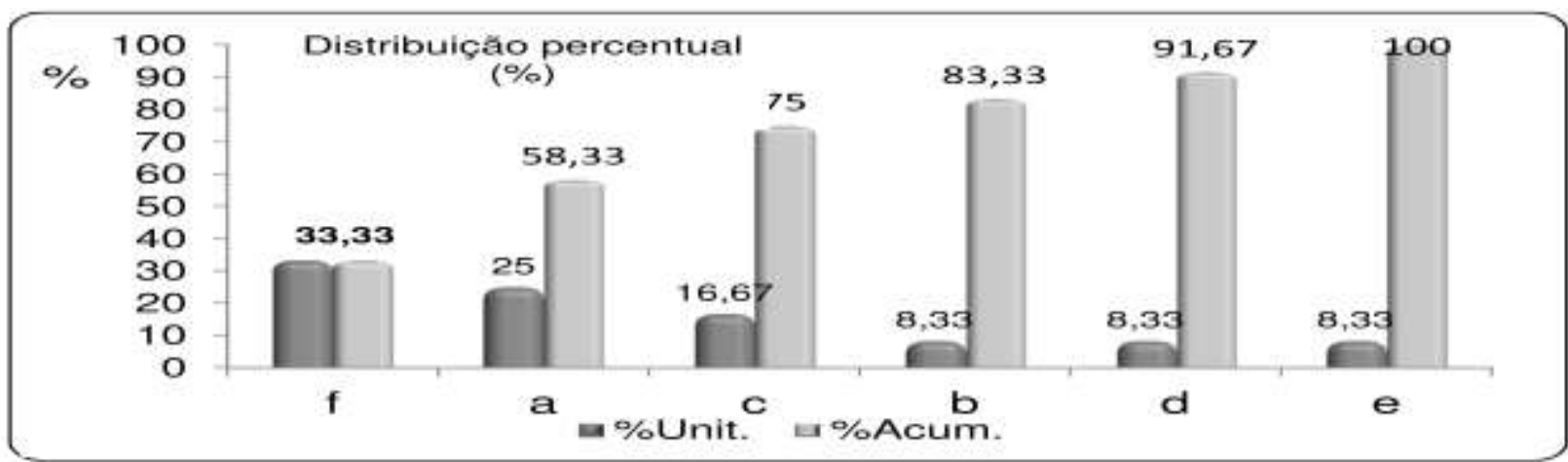

Fonte: dados e informações da pesquisa (2021).

A Figura 1 ilustra um Gráfico de Pareto, lista os motivos por ordem de priorização. Dos motivos observa-se que o motivo "f" $(33,33 \%)$ indicado em "E" da Tabela 1: Não sabiam que tais certificados eram requeridos pela empresa foi o que mais se aproximou da casa dos $20 \%$ Acum., portanto, se esse motivo for tratado primeiro, os demais tendem a ser resolvidos.

Vale lembrar que, de acordo com Carpinetti (2016), para se elaborar um Gráfico de Pareto é preciso determinar o \%Unit. e o \%Acum. das série de elementos sob estudo e o \%Acum. que estiver próximo da casa dos $20 \%$ se for resolvido, os demais tendem ser solucionados. Nesse contexto, uma proposta à melhoria foi elaborada. 


\subsection{Apresentação de uma proposta para que se possa otimizar o processo admissional dos seus trabalhadores, isso mediante o ciclo PDCA}

Como proposta de melhoria elaborou-se um Planejamento Estratégico (PE) mostrado no Quadro 1, sobre o que se deve fazer para evitar que novos gargalo(s) relacionados à entrega ou apresentação de documentos na etapa de admissão de trabalhadores ocorra.

Quadro 1 - 5W2H como proposta à não ocorrência de gargalo.

\begin{tabular}{|c|c|c|c|}
\hline 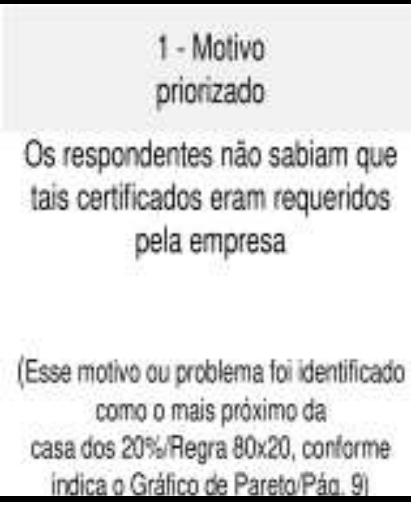 & \begin{tabular}{l}
\multicolumn{1}{c|}{$\begin{array}{l}\text { 2- What } \\
\text { O que será feito } \\
\quad \text { (etapas) }\end{array}$} \\
Solicitar o(a) candidato(a), ainda na \\
fase de recrutamento que ele \\
apresente o certificado sobre o curso \\
Básico e do curso SEP para que ele \\
possa prosseguir como candidato \\
como eletricista na empresa.
\end{tabular} & \begin{tabular}{l}
\multicolumn{1}{c}{$\begin{array}{c}3 \cdot \text { Why } \\
\text { Por que será feito } \\
\quad \text { (justificativa) }\end{array}$} \\
Para que no momento da admissão \\
ocorra a entrega de todos os \\
documentos necessários e evite, \\
assim, atrasos (gargalo) na \\
admissão e impedimento do acesso \\
do trabalhador a qualquer das FPP.
\end{tabular} & $\begin{array}{l}\text { 4- Where } \\
\text { Onde será teito } \\
\quad \text { (local) } \\
\text { Na etapa de recrutamento do } \\
\text { trabalhador. }\end{array}$ \\
\hline $\begin{array}{l}\text { 5-When } \\
\qquad \begin{array}{l}\text { Quando será feito } \\
\text { (tempo) }\end{array} \\
\text { Para evitar gargalos no setor de } \\
\text { produçāo, recomenda-se que esse } \\
\text { Planejamento Estratégico seja } \\
\text { colocado em prática assim que o } \\
\text { mesmo for aprovado. }\end{array}$ & $\begin{array}{l}\text { 6. Who } \\
\text { Por quem será feito } \\
\text { (responsabilidade) } \\
\text { Pelo Sr. Joanas Barbha Nova (nome } \\
\text { fictício), gestor dos } \\
\text { Recursos Humanos da empresa. }\end{array}$ & $\begin{array}{l}\begin{array}{c}\text { 7-How } \\
\text { Como será feito } \\
\text { (método) }\end{array} \\
\text { Na etapa do recrutamento: } \\
\text { Deixar claro para o candidato que } \\
\text { para continuar como candidato à } \\
\text { vaga de eletricista ele precisa } \\
\text { apresentar os certificados previstos } \\
\text { no item } 10.8 \text { da NR-10, posto pelo } \\
\text { Ministério do Trabalho e Emprego. }\end{array}$ & $\begin{array}{l}\begin{array}{l}\text { 8. How much } \\
\text { Quanto custará fazer } \\
\quad \text { (custo) }\end{array} \\
\text { As instruçōes devem ocorrer } \\
\text { internamente, portanto colocar esse } \\
\text { PE em curso pode ser considerado } \\
\text { uma rotina normal e não vai gerar } \\
\text { custos. }\end{array}$ \\
\hline
\end{tabular}

Fonte: autores (2021).

O Quadro 1 refere-se ao PA e visa orientar o gestor sobre o que se deve fazer para evitar gargalos quando se admite trabalhadores. Cada etapa indica:

1 - O motivo ou o problema que foi priorizado;

2 - What?/O que será feito: trata do que será feito na etapa/fase de recrutamento;

3 - Why?/Por que será feito: refere-se ao o que se pretende, para evitar atrasos;

4 - Where?/Onde será feito: etapa onde o PA será realizado;

5 - When?/Quando será feito: indica quando o PA deverá ser iniciado;

6 - Who?/Por quem será feito: indica a pessoa responsável pela implantação do PA;

7 - How?/Como será feito?: mencionar a necessidade de apresentar os certificados;

8 - How much/Custo: refere-se ao quanto será gasto à implantação do PA.

Vale lembrar que, segundo Carpinetti (2012), a ABNT NBR 45001 (2018) e Periard (2009), um PA estabelece o passo-a-passo para solucionar o problema que foi priorizado e representa a etapa "P" do ciclo PDCA. Quanto às etapas " $D$ ', 'C" e "A":

D - Compreende o colocar o PA ou a etapa "P" em prática;

C - É verificar se o desenvolvimento do PA está ou não conforme o planejado;

A - Caso os objetivos tenham sido alcançados, então reconhece-se a eficácia do PA 
que foi implementado, porém periodicamente se faz novo ciclo PDCA com vistas implementar melhoria contínua no cenário analisado.

\section{Conclusão}

O objetivo geral desta pesquisa foi saber de que maneira se pode otimizar a etapa de admissão da UPTEC com vistas evitar que os trabalhadores atrasem a entrega de dois certificados sobre curso em área da elétrica: um curso denominado básico, e o outro relacionado ao SEP, cursos esses normatizados pela NR-10, item 10.8 indicados pela Portaria Ministerial $\mathrm{n}^{\circ}$ 3.214 do Ministério do Trabalho e do Emprego. Nesse contexto, o que foi delineado foi cumprido mediante realização dos três objetivos específicos: a)Para levantar os dados e as informações necessárias à elaboração desse estudo, um questionario foi encaminhado via e.mail; devido ao momento de pandemia relacionado ao CoVid-19, para 12 trabalhadores da UPTEC, consolidando, assim, a etapa do Princípio básico de Gestão de Informação; b)Os motivos foram listados, processados, priorizados e os resultados foram disponibilizados mediante o uso de ferramentas da qualidade, e c)Uma proposta, nos moldes do Ciclo PDCA foi elaborada e apresentada à melhoria do cenário avaliado na UPTEC. A ênfase foi dada à etapa P, de Planejamento, porque as demais demandam tempo de implementação da proposta.

Nesse cenário conclui-se que o que se esperava nesse estudo foi realizado tanto em relação à aplicação de ferramentas da qualidade, quanto sobre o Planejamento Estratégico nos moldes do Ciclo PDCA. Nesse contexto, sobre a utilização de ferramentas da qualidade verificou-se que tais podem ser aplicada em situações diversas, tanto à coleta de dados e de informações, quanto para se processar, apresentar e destinar os resultados à tomada de decisões cabíveis pela gestão da empresa. Sobre o Ciclo PDCA verificou-se que essa é uma ferramenta propícia para organizar o passo a passo sobre o que fazer, para que os objetivos esperados pela organização sejam alcançados. Por fim, conclui-se que otimização da etapa de admissão sobreveio da necessidade da UPTEC informar ao candidato que é necessário apresentar os certificados à empresa ainda na fase de recrutamento para que este ou a empresa perca tempo durante essa fase no processo admissional.

Para firmar os conceitos e a praticidade do estudo, sugere-se que novas pesquisas sejam realizadas em tempo devido, com uma maior representatividade ou amostragem, no caso, de trabalhadores.

\section{Referências}

Alonço, G. (2018). As sete ferramentas da qualidade - Tudo o que você precisa saber! pdf. https://certificacaoiso.com.br/as-sete-ferramentas-da-qualidade/.

Associação Brasileira De Norma Técnica (ABNT). (2018) NBR ISO 45001. Sistema de gestão de saúde e segurança ocupacional - Requisitos com orientação para uso. Norma traduzida. ISBN 978.85.07.07514-1. www.iso.org.

Borko, H. (1968). Ciência da Informação: O que é isso? Documentação Americana, v.19, n.1, p.3-5, Jan. 1968. https://edisciplinas.usp.br/pluginfile.php/ 2532327/mod_resource/content/1/Oque\%C3\% A9CI.pdf.

Branjão, J. K. M. (2016). Gestão de Produtos tangíveis e intangíveis. https://pt. slideshare.net/juscimarakelle/gesto-de-produtos-tangveis-e-intangveis65939497.

Brasil (1977). Lei Federal $n^{\circ}$ 6.514, de 22 de dezembro de 1977. Altera o Capítulo V do Título II da Consolidação das Leis do Trabalho, relativo a segurança e medicina do trabalho e dá outras providências. http://www.planalto.gov.br/ccivil_03/LEIS/L6514.htm.

Brasil (1978). Portaria Ministerial $n^{\circ}$ 3.214, de 8 de junho de 1978, Normas de Segurança e Medicina do Trabalho. http://trabalho.gov.br/participacao-socialmtps/participacao-social-do-trabalho/legislacao-seguranca-e-saude-no-trabalho/item/3679-portaria-3-214-1978.

Camargo, W. (2011). Controle de Qualidade Total. In: Instituto Federal de Educação, Ciência e Tecnologia - Paraná - Educação a Distância. Curitiba-PR: eTec. 2011. http://ead.ifap.edu.br/ netsys/public/livros/LIVROS\%20SEGURAN \%C3\%87A\%20DO\%20 TRABALHO/M\%C3\%B3dulo\%20I/Livro\% 20Controle\%20da\%20Qualidade\% 20Total.pdf.

Carpinetti, L. C. R. (2012). Gestão da qualidade: conceitos e técnicas. (2. ed.) Atlas.

Carpinetti, L. C. R. (2016). Gestão da qualidade: conceitos e técnicas. (3. ed.) Atlas.

Castro, S. de. (2006). NR-10: curso básico de segurança em instalações e serviço em eletricidade. Manual de treinamento.

https://pt.slidesharenet/Santosde/curso-bsico-de-nr-10-apostila. 
Chiavenato, I. (2010). Comportamento organizacional. Elsevier.

Chiavenato, I. (2014). Gestão de pessoas: o novo papel dos recursos humanos nas organizações. (4. ed.) Manole,

Conselho Regional de Engenharia e Agronomia (CREA). (2005). Resolução $n^{\circ} 1010$, de 22 de dgosto de 2005. Dispõe sobre a regulamentação da atribuição de títulos profissionais, atividades, competências e caracterização do âmbito de atuação dos profissionais inseridos no Sistema Confea/Crea, para efeito de fiscalização do exercício profissional. http://www.abepro.org.br/arquivos/websites/1/1010-05.pdf.

Coutinho, K. (2020). O que faz um engenheiro de produção: as atribuições desta Profissão. pdf. https://www.tuacarreira.com/o-que-faz-umengenheiro-deproducao/.

Dinsmore, P. C. \& Cavalieri, A. M. (Org.). (2013). Como se tornar um profissional em gerenciamento de projetos: livro base de preparação para certificação PMP - Project Management Professional. (4. ed.) Qualitymark,

Dunder, K. (2020). Recém-formados sofrem para conquistar o primeiro emprego. Artigo. https://noticias.r7.com/educacao/recemformadossofremparaconquistar-o-primeiro-emprego-30012020.

Escola Nacional da Inspeção do Trabalho (ENIT). [2020]. Norma Regulamentadora (NR) 10. https://enit.trabalho.gov.br/portal/images/Arquivos_SST/SST_NR/NR-10.pdf.

Gil, A. C. (1994). Métodos e técnicas de pesquisa social. (4. ed.) Atlas.

Gil, A. C. (2017). Como elaborar projeto de pesquisa - (6. ed.) Atlas.

Gonçalves, J. E. L. (2000). As empresas são grandes coleções de processos. RAE - Revista de Administração de Empresas, São Paulo, n.40, p.6-19, Jan./Mar. 2000 .

Harrington, H. J. (1993). Aperfeiçoando processos empresariais. Makron Books.

Jung, C. F. (2004). Metodologia Para Pesquisa \& Desenvolvimento Aplicada a Novas Tecnologias, Produtos e Processos. Axcel Books do Brasil.

Junior, M. P. C. (2014). Perspectivas em ciência da informação. Pesquisa Brasileira em Ciência da Informação e Biblioteconomia, 9(2) http://hdl.handle.net/20.500.11959/brapci/25216,https://www.brapci.inf.br/index.php/ res/v/252 16.

Kayser, M. (2020). Criando o seu Planejamento Estratégico em 40 horas.https://d335 luupugsy2.cloudfront.net/cms/files/7676/ 1549475636Criando_ o_seu_Planejamento_Estratgico_em_40_horas_2.pdf.

Lakatos, E. M. \& Marconi, M. de A. (2006). Técnicas de pesquisa: planejamento e execução de pesquisas, amostragens e técnicas de pesquisa, elaboração, análise e interpretação de dados. (6. ed.) Atlas.

Lélis, E. C. (2012). Gestão da Qualidade. Pearson.

Marconi, M. de A. (2006). Técnicas de pesquisa: planejamento e execução de pesquisas, amostragens e técnicas de pesquisa, elaboração, análise e interpretação de dados. (6. ed.) Atlas.

Maroueli, C. A. (2008). Gargalos de Produção: o que são e por que devem ser eliminados. https://administradores.com.br/artigos/gargalos-de-producao-oque-sao-e-por-que-devem-ser-eliminados.

Mattede, H. (2020). O que é a NR-10? https://www.mundodaeletrica.com.br/o-que-e-a-nr-10/.

Minayo, M. C. de S. (1997). Pesquisa social: teoria, método e criatividade. (7. ed.) Vozes.

Montagner, C. A. \& Marx, H. G. (2009). Gestão da Informação Integrada. http://minhateca.com.br/Fabiano.Neves/LIVROS/FERRAMENTAS+PARA+ GEST*c3*83O, http://minhateca.com. br/Fabiano.Neves/LIVROS/GEST*c3*83O+DE+QUALIDADE/GEST*c3*83O+DA+INFORMA*c3*87*c3*83O+ INTEGRADA, 4384193.pdf.

Moura, K. (2020). Quais as atribuições de um Engenheiro de Produção? pdf. https://engenharia 360.com/atribuicoes-de-engenheiro-de-producao/.

Periard, G. (2009). O que é o 5W2H e como ele é utilizado? pdf. http://www.sobreadministracao. com/o-que-e-o-5w2h-e-como-ele-e-utilizado/.

Ponjuán Dante, G. (1998). Gestión de información en las organizaciones: principios, conceptos y aplicaciones. Chile: Universidad de Chile, 222p. (Série Gestión de Información) Brazilian Journal of Information Science, ISSN-e 1981-1640, 7, 47-69.

Rodrigues, M. V. (2004). Ações para a Qualidade. GEIQ - Gestão Integrada para a Qualidade. Padrão Seis Sigma. Classe Mundial. QualityMark,.

Santos, J. (2010). O processo de gestão e os sistemas de informações gerenciais. Pdf. https:// administradores.com.br/artigos/o-processo-de-gestao-e-ossistemas-de-informacoes-gerenciais.

Sociedade Brasileira de Pneumologia e Tisiologia (SBPT). (2020). Orientações da OMS para prevenção da COVID-19. https://sbpt.org.br/portal/covid-19oms/.

Silva, T. Da \& Tomaél, M. I. (2007). A gestão da informação nas organizações. 12(2) Artigo. http://srv-009.uel.br/revistas/uel/index.php/ informacao/article/view/1806/1540.

Slack, N. Et al. (2013). Gerenciamento de operações e de processos: princípios e práticas de impacto estratégico. Tradução: Luiz Claudio de Queiroz Faria; rev. téc.: Rogério Garcia Banolas. (2. ed.) Bookman.

Sordi, J. O. de. (2008). Gestão por Processos: uma abordagem da moderna administração. (2. ed.) Saraiva. 